CLAUDIA CRISTINA BARRILARI

\title{
AUTORREGULAÇÃO REGULADA, CRIMINAL COMPLIANCE E MECANISMOS SANCIONATÓRIOS
}

Tese de Doutorado

Orientador: Professor Titular Dr. Renato de Mello Jorge Silveira

UNIVERSIDADE DE SÃO PAULO

FACULDADE DE DIREITO

São Paulo-SP

2017 


\section{CLAUDIA CRISTINA BARRILARI}

\section{AUTORREGULAÇÃO REGULADA, CRIMINAL COMPLIANCE E MECANISMOS SANCIONATÓRIOS}

Tese apresentada à Banca Examinadora do Programa de Pós-Graduação em Direito, da Universidade de São Paulo, como exigência parcial para obtenção do título de Doutor em Direito, na área de concentração Direito Penal, sob a orientação do Professor Titular Dr. Renato de Mello Jorge Silveira

UNIVERSIDADE DE SÃO PAULO

FACULDADE DE DIREITO

São Paulo-SP 
Catalogação da Publicação

Serviço de Biblioteca e Documentação

Faculdade de Direito da Universidade de São Paulo

Barrilari, Claudia Cristina

Autorregulação regulada, criminal compliance e mecanismos sancionatórios / Claudia Cristina Barrilari ; orientador Renato de Mello Jorge Silveira -- São Paulo, 2017.

261

Tese (Doutorado - Programa de Pós-Graduação em Direito Penal, Medicina Forense e Criminologia) Faculdade de Direito, Universidade de São Paulo, 2017 .

1. Direito penal. 2. Responsabilidade penal da pessoa jurídica. 3. Crimes econômicos. 4. Corrupção. 5. Compliance. I. Silveira, Renato de Mello Jorge, orient. II. Título. 
BANCA EXAMINADORA

1

2

3

4

5 
Para Giordana,

que tanto me modificou. 


\section{AGRADECIMENTOS}

Aos colegas da Pós-Graduação da Faculdade de Direito da Universidade de São Paulo que me acompanharam durante o transcorrer do curso, com quem dividi angústias e entusiasmos, Daniela Marinho Scabbia Cury, Jennifer Falk Badaró, Heidi Florêncio Neves, Natasha do Lago e Pedro Augusto Simões da Conceição.

Ao apoio e incentivo das amigas Carla Rahal Benedetti, Laíse Franco Galvão e Waléria Garcelan Loma Garcia.

Aos professores da Universidad de Castilla-la Mancha pela calorosa acolhida na Cidade Imperial, em especial ao professor Eduardo Demétrio Crespo, pelo convívio e pela atenção e ao professor Adán Nieto Martín, pelo vigor e entusiasmo intelectual que fortaleceu a minha confiança no presente trabalho em uma preciosa discussão. Ao colega doutorando daquela instituição Oscar Lopez Rey pelo inestimável auxílio em Toledo.

À Rogéria Gieremeck, pela generosa maneira como me recebeu.

Ao meu orientador, professor titular Renato de Mello Jorge Silveira, pela confiança, pela paciência, pela atenção e pela orientação precisa.

Aqueles que, mesmo sem saber, deram fundamental apoio para a concretização do trabalho, em especial minha prima Doraci Barrilari Morelli e Maria José Constantino Petri, sempre ao meu lado, e as amigas Adriana Garcia Sant'Anna, Célia Passoni, Lucia Squizatto Azzi e Marie Nagae.

Aos meus pais, ao Marcelo, meu esposo, aos meus filhos, Franco e Giordana, minha gratidão e meu amor. 


\section{RESUMO}

BARRILARI, Claudia Cristina. Autorregulação regulada, criminal compliance e mecanismos sancionadores. 2017. 261 f. Tese (Doutorado) - Faculdade de Direito, Universidade de São Paulo, São Paulo, 2017.

O presente trabalho tem por objeto compreender o papel das empresas diante das interações existentes com o Estado e a sociedade, para apresentar uma proposta de responsabilidade penal de pessoa jurídica que tenha por base a autorregulação regulada. Nesse contexto, a responsabilidade penal da empresa surge atrelada a um mecanismo de política criminal preventiva. $O$ tema tem amparo nas normativas externas que, em âmbito global, reclamam a construção de um direito penal coeso e integrado entre os Estados que possa levar a um efetivo combate da criminalidade econômica. Embora a ideia de responsabilidade penal da pessoa jurídica esteja consolidada em vários países do mundo, no ordenamento jurídico brasileiro ainda não foi consagrada de forma ampla. A recente Lei Anticorrupção é um exemplo desse atraso. $O$ trabalho adota como ponto de partida a necessidade de que o Brasil adote a responsabilidade penal da pessoa jurídica para o combate dos crimes que ocorrem em âmbito empresarial, dando destaque para o combate ao fenômeno da corrupção. Propõe assim, a estruturação de um mecanismo preventivo, a exemplo dos sistemas jurídicos estrangeiros abordados. Tais sistemas estrangeiros, não obstante tenham bases diversas, de common law e civil law, parecem construir um sistema de responsabilidade integrado com os mecanismos autorreguladores, cujos fundamentos sinalizam bons rumos para o sistema nacional adotar.

Palavras-chave: responsabilidade penal das pessoas jurídicas; autorregulação regulada; direito administrativo sancionador; criminal compliance. 


\section{RIASSUNTO}

BARRILARI, Claudia Cristina. Autoregolamentazione regolata, criminal compliance e meccanismi sanzionatori. 2017. $261 \mathrm{f}$. Tesi (Dottoramento) - Facultà di Giurisprudenza, Università di São Paulo, São Paulo, 2017.

Lo scopo di questo studio è quello di comprendere il ruolo delle imprese rispetto alle interazioni esistenti con lo Stato e con la società, nonché quello di elaborare una proposta per la responsabilità penale della persona giuridica, che si fondi sulla autoregolamentazione regolata. In quest'ambito, la responsabilità penale della società appare legata ad un movimento di politica criminale preventiva. Questa tematica fa riferimento a normative esterne che, a livello globale, richiedono la costruzione di un diritto penale coeso e integrato tra gli stati che potrebbero portare ad una lotta efficace contro la criminalità economica. Sebbene la responsabilità penale della persona giuridica sia regolamentata nei paesi in tutto il mondo, nel sistema giuridico brasiliano non troviamo ancora che ampia e esaustiva. La recente legge anticorruzione è un esempio di questo ritardo. II lavoro parte dalla premessa della necessità di addotare in Brasile la disciplina della responsabilità penale delle persone giuridiche per combattere i reati che si verificano nell'ambito dell'impresa, mettendo in evidenza la lotta contro il fenomeno della corruzione. Propone, pertanto, di strutturare un meccanismo di prevenzione, come i sistemi giuridici stranieri analizzati. Tali ordinamenti giuridici stranieri hanno, nonostante basi diverse (common law e civil law), per poter giungere un sistema integrato di responsabilità con meccanismi di autoregolamentazione, che possano contribuire nella ricerca di nuove direzioni per il sistema interno.

Parole-chiave: responsabilità penale delle persone giuridiche; diritto penale amministrativo; autoregolamentazione regolata; criminal compliance. 


\section{RÉSUMÈ}

BARRILARI, Claudia Cristina. Autorégulation réglementée, criminal compliance e mécanisme de sanctions. 2017. 261 f. Thèse (Doctorat) - Faculté de Droit, Université de São Paulo, São Paulo, 2017

Dans cette étude, la question qui se pose est celle de comprendre le rôle des entreprises en ce qui concerne des interactions existantes avec l'Etat et la société, ainsi que présenter une responsabilité pénale des personnes morales qui se fonde sur l'autorégulation réglementée. A cet égard, la responsabilité pénale de l'entreprise semble liée à un moteur de prévention de la politique pénale. L'analyse s'appui sur les disciplines externes qui, à l'échelle mondiale, exigent la construction d'un droit pénal cohérent et intégré entre les Etats qui, par ailleurs, pourrait mener à une lutte efficace contre la criminalité économique. Bien que la responsabilité pénale des personnes morales soit consolidée dans différents pays du monde, dans le système juridique brésilien n'a pas encore été trouvé un régime complet. La récente loi anti-corruption est un exemple de ce retard. La recherche prend comme point de départ la nécessité pour le Brésil d'adopter la responsabilité pénale des personnes morales pour combattre la criminalité des enterprises, mettant en évidence la lutte contre le phénomène de la corruption. Par conséquent, il est proposé d'introduire un mécanisme de prévention, comme dans les systèmes juridiques étrangers étudiés. II parait que les systèmes étrangers envisagés ont des bases différentes, la common law et le civil law, mais pas pour construire un système intégré de responsabilité avec des mécanismes d'autorégulation, ce qui pourrait aider le système interne trouver une nouvelle direction.

Mots-clés: responsabilité pénale des personnes morales; droit administratif répressif, autorégulation réglementée; criminal compliance. 


\section{SUMÁRIO}

1 INTRODUÇÃO .13

2 SOCIEDADE, ESTADO E DIREITO: A DIMENSÃO DA AUTORREGULAÇÃO

2.1 Reconfiguração do conceito de soberania ante o binômio risco/segurança 18

2.2 Reflexões sobre a economia, a socialização e o direito reflexivo. .22

2.3 Soberania, Estado transnacional ou supranacional e Direito Penal mundial .28

2.4 Breves considerações sobre o processo de harmonização do Direito Penal europeu .32

2.5 Sociedade de risco e bem jurídico supraindividual .35

2.6 Aproximações entre a responsabilidade penal da pessoa jurídica e criminal compliance

3 AUTORREGULAÇÃO COMO FENÔMENO PREVENTIVO .46

3.1 Introdução 46

3.2 Influência das Normativas Supranacionais .52

3.2.1 Pacto Global .53

3.2.1.1 O Projeto de normas da sub-comissão de Direitos Humanos da ONU sobre a responsabilidade das empresas

3.2.1.2 Empresas e direitos humanos: possível interação

3.2.2 O combate à corrupção no espaço jurídico global: Convenção da ONU de 2003, Convenção Interamericana e os códigos de conduta como medida preventiva 60

3.2.3 Conselho Europeu: Convênios sobre Corrupção e o Grupo de Estados contra a Corrupção (GRECO)

3.2.4 Organização para a Cooperação e Desenvolvimento Econômico (OCDE). 68

3.2.5 Alguns Impactos das Convenções no Ordenamento jurídico Brasileiro 69 
3.3 Responsabilidade social da empresa e governança corporativa

3.3.1 Aspectos pontuais da responsabilidade social da empresa na Comunidade Europeia

3.3.2 Aspectos pontuais da responsabilidade social da empresa no Brasil .78

3.3.3 Interface entre governança corporativa e autorregulação. 81

3.4 Pontos de contato principais entre a responsabilidade social da empresa, a ética e a autorregulação

3.5 Ética pública e empresarial: as duas faces da moeda ..................................8

3.6 Autorregulação sob a ótica do direito público …………………..................93

3.7 Possíveis deficiências da autorregulação ..................................................100

3.8 Autorregulação nos sistemas da common law e da civil law: principais aspectos. 108

\section{DIREITO ADMINISTRATIVO SANCIONADOR E A LEI}

ANTICORRUPÇÃO.

4.1 Natureza do ilícito e Direito Administrativo sancionador 115

4.2. Notas sobre um possível Direito Administrativo sancionador brasileiro. 120

4.3 Notas sobre a lei $12846 / 13$ e os decretos que a regulamentaram: responsabilidade da pessoa jurídica sobre os atos de corrupção no Brasil.

\section{CONFLUÊNCIAS ENTRE A RESPONSABILIDADE PENAL DA PESSOA JURÍDICA E A AUTORREGULAÇÃO.}

5.1 Considerações sobre a natureza jurídica da pessoa jurídica e os modelos de responsabilidade

5.2 Responsabilidade penal da pessoa jurídica no Brasil 148

5.3 Principais aspectos da responsabilidade penal da pessoa jurídica em países de common law - EUA e Reino Unido 158

5.3.1 Notas sobre a responsabilidade da pessoa jurídica no direito americano 161

5.3.2 Notas sobre a responsabilidade da pessoa jurídica no direito britânico 
5.4 Principais características da responsabilidade da pessoa jurídica no

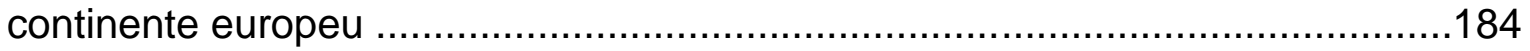

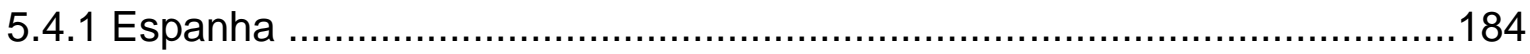

5.4.1.1 A reforma de 2010 (LO 5/2010)..........................................................188

5.4.1.2 A reforma de 2015 (LO 1 / 2015) .....................................................192

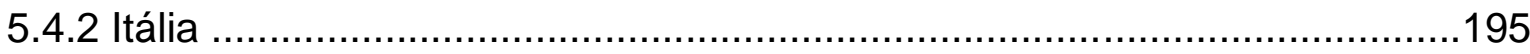

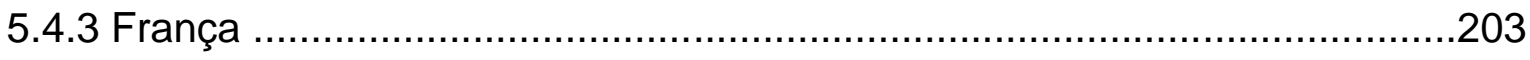

6 DERIVAÇÕES DOGMÁTICAS DA CRIMINAL COMPLIANCE E DA RESPONSABILIDADE PENAL DA PESSOA JURÍDICA...................................211

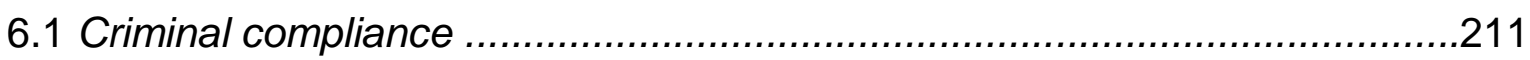

6.2 Breves considerações sobre a responsabilidade penal individual do empresário (autoria, participação e omissão) ………………………………......219

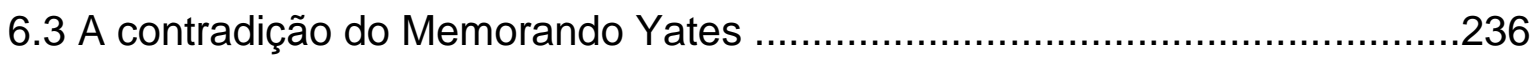

7 CONCLUSÃO

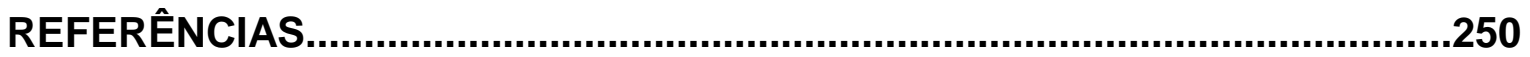




\section{INTRODUÇÃO}

A questão da chamada criminal compliance desperta dúvidas de várias ordens. Por um lado, a vida em sociedade exige constante reflexão acerca da dinâmica pela qual as relações humanas se estabelecem, seja sob a ótica das relações interpessoais, sob a ótica das relações com o Estado e, finalmente, encarada sob o prisma econômico em geral, das relações entre a sociedade e a empresa.

Contudo, quando essa reflexão aponta a existência de conflitos, o Direito é chamado para buscar uma solução equilibrada, ou, no mínimo, uma solução que melhor atenda aos anseios sociais.

Nesse contexto, diante do evidente conflito na forma de interação entre sociedade, empresa e Estado, frente às questões socioeconômicas, o objetivo é encontrar um caminho de integração entre esses elementos de modo que a lógica própria de um desses sistemas possa conviver da forma mais harmônica possível com a lógica do outro. Com isso quer-se dizer que o sistema econômico tem uma lógica que lhe é própria e que, algumas vezes, não convive com a lógica própria dos ordenamentos estatais ou com a lógica da sociedade na qual está inserido. Há uma tensão natural entre esses sistemas, ocasionada pela disputa de forças que é inerente à dinâmica apontada.

O momento atual, entre outros sinais, coloca em evidência os fracassos do desequilíbrio de forças decorrentes do fortalecimento de um desses elementos em detrimento dos demais, exige uma tomada de posição em prol de mecanismos que permitam visualizar um meio de resolução de problemas complexos.

Tudo indica que se faz necessário extrair do sistema jurídico, cuja lógica nem sempre é a mesma do sistema econômico, um meio que otimize a relação Estado, sociedade e empresa. Essa realidade acaba, por fim, em dar nova dimensão à ideia de um Direito Penal empresarial. 
Esse é o contexto no qual parece oportuno apresentar uma proposta de incentivo a mecanismos autorreguladores dentro das pessoas jurídicas de direito privado, como forma de prevenir condutas ilícitas. Por outro lado, os mecanismos preventivos acabam por gerar, simultaneamente, uma nova abordagem da responsabilidade penal individual daqueles gestores empresariais que venham a descumprir tais normativas reguladoras.

O tema faz parte de uma tendência moralizadora, responsável por assumir um compromisso ético e ordenador, reconfiguradora do exercício da atividade capitalista, que vai agir em colaboração com o Estado.

Mas convém antecipar, todavia, que se faz necessário, em um primeiro momento, compreender o papel do Estado na sociedade pós-moderna, ou seja, contextualizar o Estado ante o agigantamento e a descentralização da sociedade.

Os conflitos socioeconômicos que estão a caracterizar o panorama mundial contribuem para a busca por medidas mais efetivas para a coexistência da força do mercado, da tutela regulamentar do Estado e de uma sociedade civil mais harmônica e igualitária. Os horizontes apontam para um redimensionamento do Direito, com a fusão de ramos e teorias que se confluem com o objetivo de possibilitar uma resposta para a ebulição do fenômeno socioeconômico presente.

O Direito Penal, antes isolado na torre de última reserva da resposta estatal para os atos individuais, agora é chamado para tutelar os conflitos que surgem nesse novo panorama mundial, especialmente para as questões que se referem ao âmbito do mercado e da economia. Em síntese, o penalista, para uma resposta efetiva, precisa revisitar seus valores e dogmas até agora tidos como imutáveis, para contribuir com uma resposta efetiva.

Tudo indica que o Direito Penal passa por uma verdadeira revolução nas últimas décadas, e que a própria estrutura do tipo penal passa por mudanças significativas tanto sob ótica objetiva, com as novas teorias normativas da imputação objetiva, quanto sob ótica subjetiva, com novas teorias do dolo. Alteram-se ainda as estruturas de autoria e participação, as estruturas organizadas e complexas demandam novas teorias para o concurso de agentes. 
São novos parâmetros que vão sendo estabelecidos de acordo com as demandas da sociedade moderna, nesse contexto, está inserida a necessidade de se alargar as fronteiras do sujeito ativo no direito penal, para admitir a responsabilidade penal da pessoa jurídica.

Caso se consiga a adequada interação entre o Direito Penal e os mecanismos autorreguladores a consequência será a inauguração de uma nova fase de responsabilidade da pessoa jurídica, na qual a pessoa jurídica assume o ônus de agir positivamente dentro de limites normativos e éticos para a prevenção de ilícitos.

Nesse aspecto, é preciso estabelecer que a ideia da evolução da sociedade conduz à novos paradigmas, nos quais os fins éticos e morais devem orientar a sociedade de modo global, atuando em duas vias distintas: os fins públicos, assim considerados aqueles que devem direcionar o Estado, e também, em outra via, os fins sociais, para a vida privada em geral.

Existe, por certo, uma aproximação metodológica com a forma de desenvolvimento e de implementação do conceito de responsabilidade social da empresa. Contudo, o lastro para essa forma de controle social do Estado, que passa a contar com a colaboração das empresas por meio de instrumentos e mecanismos destinados a influir nos modelos de condutas adotados, será a previsão da responsabilidade penal da pessoa jurídica, quando a empresa falhar diante do objetivo que Ihe fora franqueado por meio da autorregulação regulada.

Vive-se um período visivelmente de transformação das relações sociais, cujo marco inicial ocorre com a queda das barreiras de espaço/tempo proporcionada pelo desenvolvimento comunicacional tecnológico. Soma-se a tanto a nova configuração do Estado e o desenvolvimento das sociedades empresárias.

A noção de soberania adquire um novo perfil com a flexibilização de seus fundamentos diante da maior interação com outras nações. Surgem, nas últimas décadas, mercados comuns e comunidades integradas por países que cedem uma parcela de sua soberania em prol de certa união de forças para funcionar como incremento do poder estatal. 
No campo privado, a consolidação da economia capitalista tem sua face mais visível com as grandes corporações cujo crescimento financeiro extrapola seu domínio territorial, com impacto econômico superior a muitas nações.

A necessidade de sintonia com o fato social do qual emana o direito exige que o mesmo se reconfigure para que esteja apto a dar uma resposta efetiva e segura. $O$ tempo presente descortina um mundo cujas fronteiras antes rigidamente fixadas, são agora maleáveis, porosas, e permitem uma simbiose entre os países soberanos.

Está em curso um período de profundas mudanças jurídicas marcado, sobretudo, por uma normativa externa e extraterritorial. Nesse cenário, os organismos internacionais, a exemplo da OIT (Organização Internacional do Trabalho), OCDE (Organização para a Cooperação e Desenvolvimento Econômico), OMC (Organização Mundial do Comércio), passam a desempenhar um papel fundamental na reconfiguração da ordem jurídica interna de cada país. Ante esses fatores, parece possível apontar o surgimento de um Direito Penal mundial.

O tema objeto deste estudo tem a missão de equacionar a responsabilidade que será imputada à pessoa jurídica que comete ilícitos, com a possibilidade de haver a previsão de um mecanismo sancionatório autorregulado pela pessoa jurídica, com finalidade preventiva, e também com a função de atenuar eventual responsabilidade caso falhar na prevenção.

Para tanto, procurar-se-á harmonizar a regulação estatal com a possibilidade de se ampliar o espectro de liberdade da pessoa jurídica, por meio da sua autorregulação. Um dos aspectos mais instigantes desse tema, que será abordado oportunamente no presente estudo, é a diferença de significado dado a ele pela civil law e o que é encontrado na common law.

A compreensão da responsabilidade penal da pessoa jurídica assume sentido diverso de acordo com o sistema legal no qual está inserido. Para aqueles países cuja base sistemática é a common law, uma das principais 
características da responsabilidade penal da pessoa jurídica é assentar-se sobre bases objetivas, a exemplo da responsabilidade civil.

Por evidente, essa característica acarreta grandes repercussões para os modelos de culpabilidade do sistema de civil law e, consequentemente, para as propostas de autorregulação. A partir dessa diferença de significado o conceito de autorregulação assume sentido diverso, de acordo com as peculiaridades de cada sistema.

Nesse passo, objeto de nosso estudo volta-se para a procura de integração entre a sanção e a prevenção, e é exatamente no sistema da common law que surge uma simbiose entre sanção e prevenção que, se não perfeita, dá mostras de efetividade maior do que a existente em outros ordenamentos.

Estabelecer qual é o sistema mais adequado, sob o prisma da efetividade e eficácia, é objetivo para qual a doutrina e os tribunais pátrios e estrangeiros não estão ainda aptos para uma resposta uníssona, desse modo, interessa pensar em meios e modos de criar um sistema que tenha aptidão suficiente para coibir a prática de crimes, e, ao mesmo tempo, dar um espaço adequado de liberdade para que a empresa se volte para os seus objetivos finais. 


\section{Conclusão}

O combate à criminalidade econômica assume particular importância hodiernamente. No específico campo da corrupção, assume papel relevante em função de seus efeitos devastadores, fenômeno este que existe em praticamente todos os países, desenvolvidos ou não. A tutela tradicional dos crimes contra a administração pública é, no entanto, insuficiente para abranger todos os fatores que devem ser levados em consideração no combate a esse fenômeno. O tratamento do tema requer uma compreensão global e multidisciplinar conforme se procurou demonstrar no capítulo 2. Nesse contexto, a tutela penal brasileira para o fenômeno da corrupção e para a criminalidade econômica em geral está ainda atrelada à responsabilidade individual, não obstante às demandas, de ordens diversas (morais, jurídicas e econômicas), para o fortalecimento das medidas sancionatórias e a expansão dessas medidas.

O conceito de corrupção em sentido amplo envolve toda uma série de delitos e irregularidades que envolvem o poder estatal. Salienta-se, nesse sentido, que transborda as fronteiras dos fatos tipificados na lei penal. Essa orientação pode ser percebida nas normativas supranacionais que versam sobre corrupção. Na prática, esse posicionamento abarca uma matiz de crimes sob a denominação de corrupção, que envolvem, além dos crimes de corrupção ativa e passiva, outros delitos, como o tráfico de influência, uso de informação privilegiada, falsificação de informação financeira, irregularidades no mercado de valores, subvenções irregulares etc

O tema merece acurada reflexão sob ótica global, no contexto das normativas internacionais. Os diferentes documentos dos organismos internacionais apresentados no capítulo 3 sugerem o estabelecimento de uma série de medidas, dentre as quais se destaca a previsão de regras de conduta para nortear as relações comerciais que podem, de forma genérica, serem reduzidos nos "dez princípios do Pacto Global da ONU".

São perceptíveis, pelas orientações contidas nos documentos internacionais, as diferentes ordens de fatores que marcam a necessidade de se 
pensar em novas formas de combate ao fenômeno em questão. Em ordem econômica, verifica-se que há um custo financeiro que prejudica a economia tanto em campo público quanto privado. Em campo público, a cada nova denúncia de desvios de recursos que deveriam ser destinados para saúde e educação, para ficar entre os setores mais sensíveis da sociedade, gera um descrédito generalizado na estrutura em que assenta a democracia, além de comprometer o crescimento e a competitividade do país e prejudicar o aumento da renda per capita. Em campo privado, o custo da corrupção reduz o investimento produtivo, desestabilizando o ambiente de negócios.

Sob o prisma jurídico, apesar da tipificação dos crimes de corrupção ativa e passiva, é necessário um novo marco que alargue as fronteiras punitivas, para abarcar o fenômeno da corrupção em todos os sentidos. É preciso consignar que a corrupção é tomada por paradigma por provocar evidente desequilíbrio na delicada trama existente entre a sociedade, o Estado e a empresa. Nesse contexto, cabe ao Direito propor uma solução que seja apta para equilibrar os fatores. Contudo o direito para atingir esse objetivo deve-se se socorrer de novas teorias, que vão torná-lo mais maleável, para que seja possível produzir uma resposta efetiva. As teorias que foram apresentadas no Capítulo 2 têm a difícil missão de dar um substrato jurídico ontológico para essas novas demandas.

Abre-se campo para conciliar a regulação pública com os novos institutos, cuja influência de legislações estrangeiras, com base jurídica diversa da nossa em alguns casos - a exemplo da lei americana e inglesa - não tem mais como ser desconsiderada.

Nesse passo, deve haver uma interação entre regulação e autorregulação das empresas. Compete ao ente público dar balizas regulatórias a que devem ficar sujeitas as empresas e, ao mesmo tempo, contar com a técnica da autorregulação para permitir que as empresas tenham certa flexibilidade interna para a adequação com a estrutura empresarial, com o campo de atividade desenvolvido e com os marcos regulatórios a que estão sujeitas.

Esse panorama demanda a adesão por parte dos Estados aos influxos das normativas externas como elemento indispensável para construir o edifício da autorregulação assentado em bases sólidas. A autorregulação, 
isoladamente considerada, é insuficiente sem uma adequada estrutura estatal que pressione as empresas a implantarem, de maneira voluntária, um sistema interno de prevenção.

Em sede administrativa, não se despreza que o reforço do aparato administrativo sancionador possa contribuir para a estruturação de um sistema de combate a corrupção. $O$ que se contesta é a suficiência ou a adequação isolada do aparato administrativo sancionador. No capítulo 4, além desses aspectos, demonstrou-se que o direito administrativo sancionador brasileiro, além de incipiente, não observa bases normativas equivalentes àquelas nas quais se amparam os sistemas de responsabilidade da pessoa jurídica em âmbito não penal.

Apesar da recente lei 12846/13 responsabilizar a pessoa jurídica em sede civil e administrativa, a estruturação da corrupção demanda a responsabilização penal da pessoa jurídica, aliada à previsão de um sistema preventivo, voltado a atuar em duas linhas: antecipadamente, no ante factum delitivo e, posteriormente, com o estabelecimento de consequências para o pos delictum.

No capítulo 5, o objeto foi a legislação comparada, tomados os sistemas de common law e civil law, para a possibilidade de, apesar da estrutura diversa de cada sistema, conciliar a responsabilidade da pessoa jurídica com a autorregulação, assentando as bases de implementação das medidas punitivas e dos mecanismos de controle.

O primeiro ponto de análise centra-se sobre os modelos de responsabilidade penal da pessoa jurídica, com o objetivo de determinar se há maior compatibilidade de um em relação a outro, se há um menor déficit dogmático em responsabilizar a pessoa jurídica identificando-se a pessoa física responsável pelo ato ou se há um grau de independência suficiente para se punir a pessoa jurídica desvinculada da pessoa física que com ela se relaciona. Toda inovação acarreta consigo o peso de alterar as estruturas até então estáveis de um sistema. 
É induvidoso que, depois que a compliance invadiu o cotidiano jurídico, há uma série de dúvidas que o assunto desperta, não só pela novidade que representa como também por sua amplitude. Cabe restringir o foco para fixar o ângulo pelo qual o tema, no âmbito criminal, deve ser compreendido.

É preciso lembrar que os programas de compliance, no Direito Penal, têm importância em frentes diversas, que vão além da conexão com a responsabilidade penal da pessoa jurídica e com o dever de garantia que pode ser imputado aos responsáveis pela implementação dos programas, os compliance officers. Seus efeitos abarcam a imputação de responsabilidade individual, tendo especial importância no enfrentamento da imprudência, em sede de crime culposo, com os deveres de cuidado do empresário e o correto atuar no enfrentamento do risco.

Conforme analisado no capítulo 6 , é preciso consignar que a utilização dos programas de compliance, em sede empresarial, podem trazer benefícios em sede processual, principalmente no contexto probatório, com a delimitação da estrutura de delegação de responsabilidade dentro da empresa, cuja correta identificação é elemento imprescindível para o exercício do direito de defesa.

O objetivo fundamental do mecanismo preventivo, se devidamente estruturado, é evitar o cometimento de delito. É necessário aproveitar as experiências estrangeiras, como a polêmica em torno da nova diretriz americana, já vista, externada pelo Memorando "Yates", para se pensar em uma estruturação correta de modo que o sistema preventivo não se transforme em mero sistema de transferência de responsabilidade.

Não há consenso em se estabelecer qual o melhor sistema de prevenção de delito ou a melhor forma de tutela. Para a nossa realidade normativa, julgamos que é necessária a construção de um modelo de prevenção que tenha por base a responsabilidade penal da pessoa jurídica. Há todo um somatório de fatores que foram expostos nos capítulos anteriores que despertam para essa nova fase regulatória. 
A introdução da responsabilidade penal da pessoa jurídica no nosso ordenamento jurídico, construído sobre bases de responsabilidade autônoma e desvinculada da pessoa física, pode, ao lado da expressa previsão da responsabilidade individual dos dirigentes pela omissão do dever de vigilância, inaugurar um novo momento dogmático com aptidão para corrigir as construções jurisprudenciais em torno do dever de garante que, não em poucas situações, conduzem a decisões questionáveis no âmbito da segurança jurídica, até em função do risco de tangenciar a responsabilidade objetiva.

O grande mérito da responsabilidade penal da pessoa jurídica desvinculada da pessoa física, ou seja, pela criação de um sistema de culpabilidade própria, é levar em conta os esforços da pessoa jurídica na implementação de um mecanismo eficiente de prevenção de crime. Essa diferença, embora sutil, é o fiel da balança que pode dar lastro de eficácia e efetividade para os programas de prevenção, os programas de compliance.

No campo penal corporativo, as medidas pensadas e estruturadas a partir de bases éticas, orientadas não só por influxos de soft law mas também por uma consciência social direcionada ao cumprimento das normas, não se mostram suficientes para, por si próprias, passarem a mensagem comunicativa própria do sistema penal.

Qualquer comparação que se estabeleça com o sistema alemão ou italiano não é de ser aceito pelo fato de não haver similitude entre o padrão de garantia que o sistema administrativo sancionador daqueles países apresenta em face do nosso. Em Espanha, os doutrinadores que criticam a recente adoção da responsabilidade penal da pessoa jurídica, assim o fazem com apoio na estrutura do direito administrativo daquele país, que conta com a máxima garantia possível. Não é o caso do nosso Direito Administrativo sancionador e também não é o caso da Lei 8462/13.

O combate ao fenômeno dos crimes ocorridos em sede empresarial precisa ser estruturado em diferentes frentes de atuação que, somadas, possam dar um tratamento efetivo a esse tormentoso problema. 
A necessidade de um sistema criado para atuação integral deve compreender medidas voltadas para prevenir e combater a corrupção como: o bom governo corporativo; o aumento do nível de transparência tanto no setor público quanto no privado; e uma nova cultura de cumprimento normativo com apoio em pressupostos éticos. Todas essas medidas devem coexistir com a responsabilidade penal da pessoa jurídica.

Nesse contexto, um modelo de prevenção assentado em bases de responsabilidade penal da pessoa jurídica deve ser construído autonomamente, desvinculado da responsabilidade individual, ao contrário do que ocorre com o modelo de heterorresponsabilidade.

A construção de um sistema normativo adequado, efetivo e lógico, pode ter apoio nas seguintes medidas:

- tipificação da responsabilidade penal da pessoa jurídica, baseada na culpa autônoma e individual da corporação pela não adoção de um instrumento preventivo que evitasse a prática de atos ilícitos, nos moldes estabelecidos em lei;

- previsão legal de um parâmetro regulatório com a fixação de medidas específicas de prevenção a ser adotado pelas empresas, que estimulasse a pessoa jurídica a estabelecer um sistema eficaz, com ênfase em medidas que relacionassem a eficácia do sistema preventivo com a correta identificação das pessoas físicas por trás do evento ilícito, de modo a impedir que o sistema de prevenção seja utilizado para encobrir eventual responsabilidade da pessoa física;

- previsão de um código de condutas para os funcionários públicos, cuja infringência caracterize improbidade administrativa, dentre outras possíveis sanções;

- expressa previsão de parâmetros para os códigos de conduta empresariais e previsão de incentivos que funcionem como barreiras preventivas para a não realização da conduta ilícita.

A mudança de um determinado padrão normativo é sempre um processo complexo. No entanto, é preciso estar atento para as demandas que, em diferentes âmbitos, exigem a adoção de novos parâmetros e novas posturas. 
A comparação com as experiências de outros países, principalmente as recentes alterações legislativas em Espanha e França, tem o objetivo de evidenciar que as estratégias seguem a mesma via. O Brasil, por sua vez, deve acompanhar essa tendência, para se colocar ao lado dos países que procuram um modo eficiente de combater a criminalidade empresarial.

A autorregulação, atrelada à responsabilidade penal da pessoa jurídica, pode constituir um novo marco político-criminal corporativo. Evidentemente, essa mudança demanda uma nova consciência ética e social das empresas e dos indivíduos.

Nosso objetivo foi demonstrar que essa nova realidade é viável e possível. O tema é novo e está em franca construção, aberto a toda sorte de discussões e questionamentos. É nesse contexto que o presente trabalho busca fornecer subsídios que possam auxiliar na análise e na solução dos problemas que o tema desperta. 


\section{REFERÊNCIAS}

ALESSANDRI, Alberto. Note penalistiche sulla nuova responsabilità delle persone giuridiche. Rivista trimestrale di diritto penale e dell'economia (anno XV1-2 gennaio-giugno). Milano: Cedam, 2002.

AMARELLI, Giuseppe. 'Crisi' del diritto penale societário e prospettive di riforma: la responsabilità (penale?) delle persone giuridiche. AMARELLI, G.; D'ALESSANDRO, M.; DE VITA, A., II nuovo sistema sanzionatorio del diritto penale dell'economia: decriminalizzazione e problemi di effettività. Napoli: Jovene editore, 2002.

ARROYO ZAPATERO, Luis. Derecho Penal en la España de la Unión Europea. In: NIETO MARTíN, Adán; PATIÑO, Omar A. Mejía. (coords.). Estudios de derecho penal económico. Ibagué: Universidad de Ibagué, Universidad de Castilla la Mancha, 2009.

BACIGALUPO, Enrique. Derecho penal: parte general, 2a ed. Buenos Aires: Hammurabi, 1999.

BAPTISTA, Luis Olavo. Contratos internacionais. São Paulo: Lex, 2011.

BARBOSA, Julianna Nunes Targino. A culpabilidade na responsabilidade penal da pessoa jurídica. Dissertação de mestrado. Faculdade de Direito da Universidade de São Paulo. 2014.

BARBERO SANTOS, Marino. Reponsabilidad Penal de la Empresa? Actualidad Penal 23 Junio 1987.

BARROS, Sérgio Rezende de. Direitos humanos: paradoxo da civilização, Belo Horizonte: Del Rey, 2003.

BASSIOUNI, M. Cherif. Diritto penale degli Sati Uniti d'America: substantive criminal law, tradotto da Luisella de Cataldo Neuburger. Milano: Giuffrè editore, 1985.

BECHARA, Ana Elisa Liberatore Silva. Bem jurídico-penal. São Paulo: Quartier Latin, 2014.

BECK, Ulrich. Risk Society: towards a new modernity, London: Sage, 2007.

BENEDETTI, Carla Rahal. Criminal compliance: instrumento de prevenção criminal corporativa e transferência de responsabilidade penal. São Paulo: Quartier Latin, 2014.

BLUMENBERG, Axel-Dirk; GARCIA-MORENO, Beatriz. Retos prácticos de la implementación de programas de cumplimiento normativo. In: IBARRA, Juan Carlos Hortal; IVAÑEZ, Vicente Valiente (coords). Responsabilidad de la empresa y compliance: programas de prevención, detección y reacción penal. Madrid: Edisofer, 2014. 
BOBBIO, Norberto. Locke e o direito natural, Brasilia: Ed. Unb, 1997.

BOTTINI, Pierpaolo, TAMASAUSKAS, Igor Sant'Anna. A controversa responsabilidade objetiva na Lei ํo 12846/13. Revista do Advogado, no 125 (dezembro de 2014). Associação dos Advogados de São Paulo. 2014.

BRAVO, Jorge dos Reis. A tutela penal dos interesses difusos: a relevância criminal na protecção do ambiente, do consumo e do patrimônio cultural, Coimbra: Coimbra editora, 1997.

BUSATO, Paulo César; REINALDET, Tracy Joseph. Crítica ao uso dogmático do compliance como eixo de discussão de uma culpabilidade de pessoas jurídicas. GUARAGNI, Fábio André; BUSATO, Paulo César (coords). Compliance e direito penal. São Paulo: Atlas, 2015.

CABALLERIA, Marcos Vaquer. Corrupción pública y ordenamiento jurídico. In: MENDIETA, Manuel Villoria; FELIÚ, José María Gimeno; BIELSA, Julio Tejedor (coords.). La corrupción en España: ámbitos, causas y remédios jurídicos. Barcelona: Atelier, 2016.

CALATAYUD, Manuel Maroto. Liberalismo versus neocorporativismo: los discursos de la autorregulación como discursos legitimantes. JIMÉNEZ, Luis Arroyo, MARTín, Adán Nieto. (coords.) Autorregulación y sanciones. Valladolid: Editorial Lex Nova, 2008.

Autorregulación y legitimidad corporativa: democracia interna y control social en partidos políticos y empresas. JIMÉNEZ, Luis Arroyo, MARTíN, Adán Nieto. (coords.) Autorregulación y sanciones, Valladolid: Editorial Lex Nova, 2008.

CARVALHOSA, Modesto. Considerações sobre a lei anticorrupção das pessoas jurídicas: lei 12846 de 2013. São Paulo: Revista dos Tribunais, 2015.

CEREZO MIR, José. Sanções penais e administrativas no direito espanhol. Revista Brasileira de Ciências Criminais ano 1, n. 2 São Paulo: Revista dos Tribunais, 1993.

CHEVALLIER, Jacques. O Estado pós-moderno, trad. e pref. Marçal Justen Filho, Belo Horizonte: Fórum, 2009.

COFFEE, John C. Corporate Criminal Liability: an introduction and comparative survey. In: Criminal responsibility of legal and collective entities: International colloquium, Berlin, may 4-6, 1998, ed. By Albin ESER, Freiburg im Breisgau:ed. Iuscrim, Max-Planck-Inst. Für ausländisches und internat. Strafrecht, 1999.

COIMBRA, Marcelo de Aguiar; BINDER, Vanessa Alessi Manzi (orgs.) Manual de compliance: preservando a boa governança e a integridade das organizações. São Paulo: Atlas, 2010.

COMPARATO, Fábio Konder. A afirmação histórica dos direitos humanos, São Paulo: Saraiva, 2004. 
COSTA, Helena Regina Lobo da. Direito penal econômico e direito administrativo sancionador: ne bis in idem como medida de política sancionadora integrada. Tese de Livre-docência. Faculdade de Direito. Universidade de São Paulo. 2013.

CRESPO, Eduardo Demetrio. Fundamento de la responsabilidad em comisión por omisión de los directivos de las empresas. In: SERRANO-PIEDECASAS, José Ramón, CRESPO, Eduardo Demetrio (coords.) Cuestiones actuales de derecho penal empresarial. Madrid: Colex, 2010.

CRETELLA JUNIOR, José. Direito administrativo comparado, São Paulo: Edusp José Bushatsky, 1972.

DALLARI, Dalmo de Abreu. Elementos de Teoria Geral do Estado, Saraiva, São Paulo, 1991.

DARNACULLETA Y GARDELLA, Maria Mercè. Autorregulación y derecho público: la autorregulación regulada. Madrid: Marcial Pons. 2005.

-La autorregulación regulada en la doctrina anglosajona y continental-europea JIMÉNEZ, Luis Arroyo, MARTíN, Adán Nieto. Autorregulación y sanciones. Navarra: Arazandi, 2015.

DAVID, René, Os grandes sistemas de direito contemporâneo, São Paulo: Martins Fontes, 1998.

DECAUX, Emmanuel. Déclarations et conventions em droit international. Cahier du Conseil Constitutionnel n. 21 - janvier, 2007. http://www.conseilconstitutionnel.fr/conseil-constitutionnel/francais/nouveaux-cahiers-du-

conseil/cahier-n-21/declarations-et-conventions-en-droit-international.50561.html

DELMAS-MARTY, Mireille. A Imprecisão do Direito: do Código Penal aos Direitos Humanos. Trad. Denise Radanovic Vieira. Barueri: Manole, 2005.

Los procesos de interacción. DELMAS-MARTY, Mireille; PIETH, Mark; SIEBER, Ulrich. (Coord.). Los caminos de la armonización penal. Valencia: Tirant lo Blanch, 2009.

CHUNG, Daniel P. Individual Accountability for Corporate Wrongdoing In: Harvard Law School Forum on Corporate Governance and Financial Regulation https://corpgov.law.harvard.edu/2015/09/21/individual-accountability-for-corporatewrongdoing/\#more-71670

DIAS, Jorge de Figueiredo. Questões fundamentais do direito penal revisitadas. São Paulo: Revista dos Tribunais, 1999.

DOTTI, Rene Ariel. Curso de direito penal: parte geral, Rio de Janeiro: Forense, 2004.

ESPINAR, José Miguel Zugaldía La responsabilidad penal de empresas, fundaciones $y$ asociaciones -presupuestos sustantivos y procesales. Valencia: Tirant lo Blanch, 2008. p.12 
FALCONE, Andrés. Elementos para a aplicação da teoria do autor detrás do autor no direito penal empresarial. In: SAAD-DINIZ, Eduardo; ADACHI, Pedro Podboi; DOMINGUES, Juliana Oliveira (coords.) Tendências em governança corporativa e compliance. São Paulo: LiberArs, 2016.

FARIA, José Eduardo. Direitos humanos e globalização: notas para uma discussão. In Estudos avançados 11 (30) 1997.

El derecho en la economia globalizada. Madrid: Trotta, 2001.

FEIJOO SÁNCHEZ, Bernardo. El delito corporativo en el código penal español: cumplimiento normativo y fundamento de la responsabilidad de las empresas. Pamplona: Civitas, 2016.

FERRAJOLI, Luigi. Derecho y garantias, Madrid, Trotta, 2006.

FOFFANI, Luigi. Bases para una imputación subjetiva de la persona moral. Hacia una culpabilidad de las personas jurídicas? Revista Nuevo Foro Penal. Vol. 6, n. 75, 2010.

FRANCO, Affonso Arinos de Mello. Responsabilidade criminal das pessoas jurídicas. Rio de Janeiro: Graphica Ypiranga, 1930.

GARCIA DE ENTERRÍA, Eduardo. Democracia, jueces y control de la administración. $6^{\circ}$ ed. Navarra: Aranzandi, 2009.

GARDNER, William L.; SRERE, Mark A.; CONWAY, Amy J. Department of justice revised principles or prosecution of business organizations require increased corporate vigilance. Morgan Lewis Counselors at Law. Fev/2003. http://www.morganlewis.jp/pubs/05D9B3F2-D856-4345-

87FA02B6912BD6C1 Publication.pdf

GIOVINE, Ombretta di. Lineamenti sostanziali del nuovo illecito punitivo. In Reati e responsabilità degli enti: guida al d. Igs. 8 giugno 2001, no 231. LATTANZI, Giorgio (org.) Milano: Giuffrè editore, 2010.

GOBERT James. Corporate criminal liability - what is it? How does it work in UK? FIORELLA, Antonio e STILE, Alfonso Maria. Corporate criminal liability and compliance programs. (First colloquium Sapienza University of Rome) Napoli: Jovene editore, 2012.

GÓMEZ-JARA DíEZ,Carlos. Fundamentos modernos de la responsabilidad penal de las personas jurídicas (bases teóricas, regulación internacional y nueva legislación española). Buenos aires: Julio Cesar Faira editor, 2010.

Delito corporativo y responsabilidad penal de las personas jurídicas: un desarrollo coherente de la jurisprudencia del Tribunal Supremo. In: Diario La Ley, № 8830, de 23 de septiembre de 2016. 
GÓMEZ DE LA TORRE, Ignacio Berdugo e CAPARRÓS, Eduardo A. Fabián. Corrupción y derecho penal: nuevos perfiles, nuevas respuestas. Revista Brasileira de Ciências Criminais n 81. São Paulo: Revista dos Tribunais, 2009.

GONZALEZ. Roberto Sousa. Governança corporativa: o poder de transformação das empresas. São Paulo: Trevisan, 2012.

GRECO FILHO, Vicente; RASSI, João Daniel. O combate à corrupção e comentários à lei de responsabilidade de pessoas jurídicas (lei 12846, de 1ํ de agosto de 2013). São Paulo: Saraiva, 2015.

GRECO, Luís e LEITE, Alaor. O que é e o que não é a teoria do domínio do fato sobre a distinção entre autor e partícipe no direito penal. Revista dos Tribunais, 933, julho de 2013.

GRINOVER, Ada Pellegrini. O processo: estudos e pareceres. São Paulo: Perfil. 2005.

JIMÉNEZ, Luis Arroyo. Introducción a la autorregulación In: JIMÉNEZ, Luis Arroyo, NIETO MARTINN, Adán. Autorregulación y sanciones. Valladolid: Editorial Lex Nova, 2008,

HASSEMER, Winfried. Direito penal libertário. Belo Horizonte: Del Rey, 2007.

LASCURAÍN, Juan Antonio. La responsabilidad penal individual por los delitos de empresa. In MARTIN, Adán Nieto (coord) Manual de cumplimiento penal en la empresa. Valencia: Tirant lo Blanch, 2015.

LEELEEA Shailendrasingh. Lutte anti-corruption: gestion des risques et compliance. Paris: Lamy. 2013.

LEWANDOWSKI, Enrique Ricardo. Proteção dos direitos humanos na ordem interna e internacional, Rio de Janeiro: Forense, 1984.

LOTTINI, Riccardo. La responsabilità penale delle persone giuridiche nel diritto inglese. Milano: Giuffrè editore. 2005.

MACHADO FILHO, Claudio Pinheiro. Responsabilidade social e governança: o debate $e$ as implicações (responsabilidade social, instituições, governança e reputação). São Paulo: Cengage Learning, 2006.

MACHADO, Marta Rodriguez de Assis. Sociedade do risco e direito penal: uma avaliação de novas tendências político-criminais. São Paulo: Ibccrim, 2005.

MACHADO, Paulo Affonso Leme. Direito ambiental brasileiro. São Paulo: Malheiros, 1998.

MAEDA, Bruno Carneiro. Programas de Compliance Anticorrupção: importância e elementos essenciais. In: DEL DEBBIO, Alessandra, MAEDA, Bruno Carneiro, AYRES, Carlos Henrique da Silva. (coords.) Temas de anticorrupção e compliance. Rio de Janeiro: Elsevier, 2013. 
MAGLIE, Cristina de. L'Etica e II mercato: la responsabilitá penale delle società. Milano: Giuffrè, 2002.

MANACORDA, Stefanno. La responsabilité des personnes morales Et Tharmonisation pénale européenne: modeles normatifs et obstacles théoriques. GIUDICELLI-DELAGE, Geneviève; MANACORDA, Stefano (coords.). La reponsabilité pénale des personnes morales: perspectives européennes et internationales, Paris: Société de législation comparée, 2013.

MARCHETTI, Anne M. Beyond Sarbanes-Oxley Compliance: effective enterprise risk management. New Jersey: John Wiley \& sons, 2005.

MARTIN CHENUT, Katia. Droits de L'homme et responsabilité des entreprises: les "príncipes directeurs des Nation Unies". In: GIUDICELLI-DELAGE, Geneviève; MANACORDA, Stefano (coords.). La reponsabilité pénale des personnes morales: perspectives européennes et internationales, Paris: Société de législation comparée, 2013,

MARTIN, Luis Gracia. Prolegômenos para a luta pela modernização e expansão do direito penal e para a crítica do discurso de resistência. Trad. De Érica Mendes de Carvalho, Porto Alegre: Sergio Antonio Fabris Ed., 2005.

MELLO, Celso Antonio Bandeira de. Grandes temas de direito administrativo, São Paulo: Malheiros. 2009.

MELLO, Rafael Munhoz. Sanção administrativa e o princípio da legalidade. Revista Trimestral de Direito Público, n. 30. São Paulo: Malheiros, 2000.

MESTRE, Aquiles. Las personas Morales y su responsabilidad penal (asociaciones, corporaciones, sindicatos) Madrid: Gongora, 1930.

MILARÉ, Édis. Direito do ambiente: doutrina, prática, jurisprudência, glossário. $2^{\circ}$ ed. São Paulo: RT, 2001.

MILITELLO, Vicenzo. The Basis for Criminal Responsibility of Collective Entities in Italy. In: Criminal responsibility of legal and collective entities: International colloquium, Berlin, may 4-6, 1998, ed. By Albin ESER, Freiburg im Breisgau:ed. Iuscrim, Max-Planck-Inst. Für ausländisches und internat. Strafrecht, 1999.

MITCHELL, Ezra Wasserman. Deferred Corporate Prosecution Agreements as Corrupt Regime: The Case for Prison, In Case Research Paper Series in Legal Studies, (6), 2015 http://ssrn.com/abstract=2558748

MONDACA, Iván Navas. Los códigos de conducta y el derecho penal económico. SILVA SÁNCHEZ, Jesús-María; FERNÁNDEZ, Raquel Montaner (coords.). Criminalidad de empresa y compliance: prevención y reacciones corporativas. Barcelona: Atelier, 2013.

MONTIGNY, Philippe. L'entreprise face à la corruption internationale. Paris: Ellipses. s/d. 
NIETO MARTíN, Adán. El Cumplimiento Normativo. In Manual de cumplimiento penal en la empresa. NIETO MARTíN, Adán (dir.) Valencia: Tirant lo Blanch, 2015.

De la Ética Pública al Public Compliance: sobre la prevención de la corrupción en las administraciones públicas. NIETO MARTíN, Adán; CALATAYUD, Manuel Maroto. Public compliance: prevención de la corrupción en administraciones públicas y partidos políticos. Cuenca: Ediciones de la Universidad de Castilla-La Mancha, 2014.

La responsabilidad penal de las personas jurídicas: esquema de um modelo de responsabilidad penal. In: Nueva Doctrina Penal. 2008/A. Buenos Aires: Del Puerto, 2008.

La responsabilidad penal de las personas jurídicas: un modelo legislativo. Madrid: Iustel, 2008.

Responsabilidad social, gobierno corporativo y autorregulación: sus influencias en el derecho penal de la empresa. Polít. Crim. N 5, 2008, A3-5. (http://www.politicacriminal.cl/n 05/a 3 5.pdf)

NOBAJAS, María Soledad Gil. El actuar en lugar de otro y la responsabilidad penal de las personas jurídicas: significado previo y posterior a la reforma del Código Penal. Revista Penal, 312013.

NOLAN, Lord. Normas de conduta para a vida pública. tradução de Standards in public life. Brasilia: ENAP, 1997.

OLIVARES, Gonzalo Quintero ROSELL, Núria Torres. Derecho penal constitucional. Valencia: Tirant lo Blanch, 2015.

OGUS, Anthony I. Regulation: legal form and economic theory. Oxford: Hart publishing, 2004.

http://encyclo.findlaw.com/9400book.pdf

Self-regulation. Encyclopedia of law and economics.

OLGIATI, Vittorio. Direito positivo e ordens sócio-jurídicas: um "engate operacional" para uma sociologia do direito europeia. In Direito e globalização econômica: implicações e perspectivas. FARIA, José Eduardo. (org.). São Paulo: Malheiros, 1988.

OLIVEIRA, Ana Carolina Carlos de. Direito de intervenção e direito administrativo sancionador: o pensamento de Hassemer e o direito penal brasileiro. Dissertação de mestrado. Faculdade de Direito da Universidade de São Paulo, 2012.

OSÓRIO, Fábio Medina. Direito administrativo sancionador, ㄴo ed., São Paulo: Revista dos Tribunais, 2005.

PARDO, José Esteve. Autorregulación: génesis y efectos. Navarra: Editorial Arazandi. 2002. 
PRADO, Luis Régis. Bem jurídico-penal e constituição. 3ª̣ed. São Paulo: Revista dos Tribunais, 2003.

Crimes contra o ambiente: anotações à Lei 9605, de 12 de Fevereiro de 1998. 2 ed. São Paulo: Revista dos Tribunais, 2001.

Responsabilidade penal da pessoa jurídica: fundamentos e implicações. In: PRADO,Luiz Régis. E DOTTI, René Ariel. Responsabilidade penal da pessoa jurídica: em defesa do princípio da imputação penal subjetiva. São Paulo: Revista dos Tribunais, 2013.

PÉREZ, Carlos Martínez Buján. Bien jurídico y derecho penal económico. In CRESPO, Eduardo Demetrio e CALATAYUD, Manuel Maroto. Crisis financiera y derecho penal económico Madrid: Edisofer, 2014.

PIERGALINNI, Carlo. I reati presupposto della responsabilità dell'ente e l'apparato sanzionatorio. LATTANZI, Giorgio (org.). Reati e responsabilità degli enti: guida al d. Igs. 8 giugno 2001, no 231. Milano: Giuffrè, 2010.

PIMENTEL, Manoel Pedro. Direito penal econômico. São Paulo: Revista dos Tribunais, 1973.

PIOVESAN, Flávia. Direitos humanos e o direito constitucional internacional, São Paulo: Max Limonad, 1996.

PITTA, André Grünspun. Processo administrativo sancionador no mercado de valores mobiliários: o uso da prova indiciária, in YARSHELL, Flávio Luiz; PEREIRA, Guilherme Setoguti (coords) Processo societário vol. II São Paulo: Quartier Latin, 2015.

PRINS, Adolphe. Ciência penal e direito positivo. Lisboa: Livraria clássica editora, 1915.

PRITTWITZ, Cornelius. A função do direito penal na sociedade globalizada do risco - defesa de um papel necessariamente modesto, Desenvolvimentos atuais das ciências criminais na Alemanha, AMBOS, Kai; BÖHM, Maria Laura. Brasília: Gazeta Jurídica, 2013.

POLITANÒ, Domenico. Diritto penale, 6⿳⺈ ed. Torino: Giappichelli, 2015.

RÁO, Vicente. O Direito e a vida dos direitos. $5^{\mathbf{a}}$ ed. São Paulo: Revista dos Tribunais, 1999.

RASSI, João Daniel. Imputação das ações neutras e o dever de solidariedade no direito penal. São Paulo: Libers Ars, 2014.

REALE, Miguel. O direito como experiência: introdução à epistemologia jurídica. $2^{\circ}$ ed., São Paulo: Saraiva, 1992.

REICH, Norbert. Formas de socializacion de la economia: reflexiones sobre el post-modernismo en la teoria jurídica. ATIENZA, Javier Corcuera, HERRERA, Miguel Angel Garcia. (coords.) Derecho y economia en el estado social. Madrid: Tecnos, 1988. 
RODRIGUEZ, Cristina Méndez. La corrupción e el marco del corpus júris In: RODRIGUEZ, Laura Zúniga; RODRIGUEZ, Cristina Méndez e DIAZ-SANTOS, Maria do Rosário Diego. (coords.). El derecho penal ante la globalización. Madrid, Colex, 2002.

ROTH, André Noël. O direito e crise: fim do estado moderno? In Direito e globalização econômica: implicações e perspectivas. FARIA, José Eduardo. (org.). São Paulo: Malheiros, 1988.

ROTSCH, Thomas. Criminal compliance. InDret. Revista per a l'Anàlisi del Dret. Barcelona, enero de 2012. http://www.indret.com/pdf/876a.pdf

SAAD-DINIZ, Eduardo. Fronteras del normativismo: a ejemplo de las funciones de la información en los programas de criminal compliance. Revista da Faculdade de Direito da Universidade de São Paulo, v. 108, 2013.

SALES, Sheila Jorge Selim de. Anotações sobre o princípio Societas delinquere non potest no direito penal moderno: um retrocesso praticado em nome da política criminal? PRADO, Luis Régis; DOTTI, René Ariel. Responsabilidade penal da pessoa jurídica: em defesa do princípio da imputação penal subjetiva. São Paulo: Revista dos Tribunais, 2013.

SALLES, Marcos Paulo de Almeida. A visão jurídica da empresa na realidade brasileira atual. Revista de Direito Mercantil, industrial, econômico e financeiro, n. 119. São Paulo, Malheiros, 2000.

SALOMÃO FILHO, Calixto. Sociedade anônima: interesse público e privado. Revista de Direito Mercantil, industrial, econômico e financeiro, n. 127. São Paulo, Malheiros, 2002.

SALVADOR NETTO, Alamiro Velludo. Da aplicação da pena às pessoas jurídicas (arts. 21 a 24). SALVADOR NETTO, Alamiro Velludo; SOUZA, Luciano Anderson de (coord.) Comentários à Lei de Crimes Ambientais - Lei no 9605/1998. São Paulo: Quartier Latin, 2009.

SARAIVA, Luciana de Pontes. Governança corporativa e auditores independentes: uma visão do Sarbanes-Oxley Act e da regulamentação da Comissão de Valores Mobiliários. In: CANTIDIAN, Luiz Leonardo, CORREA, Rodrigo (coords.). Governança corporativa, São Paulo: Lazuli, 2005.

SARAVESE, John F. White Collar and Regulatory Enforcement: What To Expect In 2015. In: Harvard Law School Forum on Corporate Governance and Financial Regulation. https://corpgov.law.harvard.edu/2015/02/05/white-collar-andregulatory-enforcement-what-to-expect-in-2015/

SARCEDO, Leandro. Compliance e responsabilidade penal da pessoa jurídica: construção de um novo modelo de imputação, baseado na culpabilidade corporativa. Tese de Doutorado. Faculdade de Direito da Universidade de São Paulo, 2014. 
SCHÜNEMANN, Bernd. Estudos de direito penal, direito processual penal e filosofia do direito. GRECO, Luis (coord.). São Paulo: Marcial Pons, 2013.

SEIN, Jose Luis Goñi. Programas de cumplimiento empresarial (compliance programs): aspectos laborales. IBARRA, Juan Carlos Hortal; IVAÑEZ, Vicente Valiente (coords). Responsabilidad de la empresa y compliance: programas de prevención, detección y reacción penal. Madrid: Edisofer, 2014.

SERRANO, Carlos Lesmes. Las infracciones administrativas y la potestad sancionadora de la administración. In Derecho penal administrativo: (ordenación del territorio, patrimonio histórico y medio ambiente) SERRANO, Carlos Lesmes et alli. Gramada: Comares, 1997.

SGUBBI, Filippo. La tutela penale degli interessi diffusi nel momento attuale. Un bilancio complessivamente negativo. In Strumenti per la tutela degli interessi diffusi della collettività: atti del Convegno nazionale promosso dalla Sezione di Bologna di Italia Nostra: Bologna, 5 dicembre 1981.

SHECAIRA, Sérgio Salomão. Responsabilidade penal da pessoa jurídica. São Paulo: Revista dos Tribunais, 1998.

SIEBER, Ulrich. Los fatores que guían la armonización del Derecho Penal. In Los caminos de la armonización penal. Coord. DELMAS-MARTY, Mireille; PIETH, Mark; SIEBER, Ulrich. Valencia: Tirant lo Blanch, 2009.

Programas de compliance en el derecho penal de la empresa: una nueva concepción para controlar la criminalidad económica. In: ARROYO ZAPATERO, Luis; NIETO MARTIN, Adán (coord) El derecho penal económico en la era compliance. Valencia: Tirant lo Blanch, 2013.

SILVA, José Afonso da. Curso de direito constitucional positivo. $24^{a}$ ed. São Paulo: Malheiros, 2005.

SILVA SANCHEZ, Jesús-Maria. A expansão do direito penal: aspectos da política criminal nas sociedades pós-industriais. São Paulo: Revista dos Tribunais. 2002.

Responsabilidad penal de las empresas y de sus organos en derecho español. In: PRADO, Luis Régis; DOTTI, René Ariel. Responsabilidade penal da pessoa jurídica: em defesa do princípio da imputação penal subjetiva. São Paulo: Revista dos Tribunais, 2013.

Memorandum Yates. InDret Revista per a l'Anàlisi del Dret, $\mathrm{n}$. 4. 2015. http://www.raco.cat/index.php//nDret/article/view/304361

Legalidad penal líquida? . InDret Revista per a l'Anàlisi del Dret, n. 3. 2015. http://www.raco.cat/index.php/InDret/article/view/304224

SILVEIRA, Renato de Mello Jorge. Direito penal supra-individual: interesses difusos. São Paulo: Revista dos Tribunais, 2003. 
Direito penal econômico como direito penal de perigo. São Paulo: Revista dos Tribunais. 2006.

Compliance, direito penal, corrupção, São Paulo: Saraiva, 2015.

Direito Penal Empresarial - A omissão do empresário como crime, Belo Horizonte: Editora D’Plácido, 2016.

Adecuación social y corrupción. DEMETRIO CRESPO, Eduardo, SERRANO-PIEDECASAS, José-Ramon (coords.) El derecho penal económico y empresarial ante los desafios de la Sociedad mundial del riesgo. Madrid: Colex, 2010.

GOMES JUNIOR, João Florêncio de Salles. Direito penal, direito administrativo sancionador e a questão do ne bis in idem: o parâmetro da jurisprudência internacional. BLAZECK, Luiz Mauricio Souza e MARZAGÃO JUNIOR, Laerte (coords.) Direito administrativo sancionador, São Paulo: Quartier Latin, 2015.

SALVADOR NETTO, Alamiro Velludo. A tutela penal do mercado de capitais e o Sarbanes-Oxley-Act: novas considerações. RUIZ FILHO, Antonio; SICA, Leonardo (coord) Responsabilidade penal na atividade econômicoempresarial. São Paulo: Quartier Latin, 2010.

SIMÕES, Pedro Coelho. A supra-individualidade como factor de superação da razão moderna. Temas de direto penal econômico, COSTA,José de Faria (coord.). Coimbra: Coimbra ed., 2005.

SOARES, Guido Fernando Silva. Common Law: introdução ao direito dos EUA, São Paulo: Revista dos Tribunais, 2000.

SOUZA, Luciano Anderson de. Direito penal econômico: fundamentos, limites e alternativas, São Paulo: Quartier Latin, 2012.

SOUZA, Susana Aires de. Direito penal das sociedades comerciais: qual o bem jurídico? Revista Portuguesa de Ciência Criminal, ano 12, Coimbra: Coimbra editores, 2002.

TANGERINO, Davi de Paiva Costa. Culpabilidade e responsabilidade penal da pessoa jurídica. Revista Brasileira de Ciências Criminais no 86, v. 18, São Paulo: Revista dos Tribunais, 2010.

TARUFFO, Michele. Sui confini: scritti sulla giustizia civile, Bologna: II Mulino, 2002.

TERRADILLOS BASOCO, Juan Maria. Corrupción, globalización y derecho penal económico. In: CRESPO, Eduardo Demetrio; SERRANO, Cuéllar; GONZÁLEZ, Nicolás (coords.) Halcones y palomas: corrupción y delincuencia econômica. Madrid: Ediciones Juridicas Castillo de Luna, 2015. 
TOMILLO, Manuel Gómez. Compliance penal y política legislativa: el deber personal y empresarial de evitar la comisión de ilícitos em el seno de las persons jurídicas. Valencia: Tirant lo Blanch, 2016.

TORRE DIAZ, Francisco Javier de la. Ética y deontologia jurídica. Madrid: Dykinson, 2000.

TRICOT, J. Corporate criminal liability in France. In FIORELLA, Antonio e STILE, Alfonso Maria (coords.). Corporate Criminal Liability and compliance programs: first colloquium. Napoli: Jovene editore, 2012.

URBINA GIMENO, Iñigo Ortiz. Responsabilidad penal de las personas jurídicas: The american way. In IBARRA, Juan Carlos Hortal; IVAÑEZ, Vicente Valiente (coords). Responsabilidad de la empresa y compliance: programas de prevención, detección y reacción penal. Madrid: Edisofer, 2014.

VARANO, Vincenzo e BARSOTTI, Vittoria: La tradizione giuridica occidentale, vol. I, Torino: Giappichelli, 2010.

VILA, Ivó Coca. Programas de Cumplimiento como forma de autorregulación regulada? In: JIMÉNEZ, Luis Arroyo, MARTín, Adán Nieto (coords.) Autorregulación y sanciones. Valladolid: Editorial Lex Nova, 2008. 